\title{
THE
}

\section{A Quantitative Comparison between 1D and 3D Source Inversion Methodologies: Application to the Middle East}

Brian M. Covellone

University of Rhode Island

Brian K. Savage

University of Rhode Island, savage@uri.edu

Follow this and additional works at: https://digitalcommons.uri.edu/gsofacpubs

Terms of Use

All rights reserved under copyright.

\section{Citation/Publisher Attribution}

Brian M. Covellone, Brian Savage; A Quantitative Comparison between 1D and 3D Source Inversion Methodologies: Application to the Middle East. Bulletin of the Seismological Society of America; 102 (5): 2189-2199. doi: https://doi.org/10.1785/0120110278

Available at: https://doi.org/10.1785/0120110278

This Article is brought to you for free and open access by the Graduate School of Oceanography at DigitalCommons@URI. It has been accepted for inclusion in Graduate School of Oceanography Faculty Publications by an authorized administrator of DigitalCommons@URI. For more information, please contact digitalcommons-group@uri.edu. 


\title{
A Quantitative Comparison between 1D and 3D Source Inversion Methodologies: Application to the Middle East
}

\author{
by Brian M. Covellone and Brian Savage
}

\begin{abstract}
We present a quantitative comparison between seismic moment tensor (MT) inversion solutions using 1D and 3D synthetic seismograms at two frequency bands for events in the Middle East, to assess the effects of 3D models on source studies. Complex geology associated with the active continental convergent margin leads to a scarcity of reliable, available data, necessitating a thorough examination of solution stability and robustness to assure an accurate description of sources with well-characterized source parameters.

Solutions were calculated for 195 events $\left(M_{\mathrm{w}}>5.5\right)$ using a full-waveform MT inversion matching both phase and amplitude. Seismic data processed at two frequency bands compares short- and long-period performance for 1D and 3D synthetic seismograms. An improvement in fit between data and synthetics is seen using 3D over 1D synthetic seismograms, especially for complex body-wave propagation and surface-wave dispersion. At short periods, 3D synthetics provide a more robust solution compared with $1 \mathrm{D}$, showing a reduction in error of the source mechanism. The percentage of double-couple components increases with the addition of 3D structure and suggests the percentage of non-double-couple components is a result of poorly constrained Earth structure. Event solutions contained in the catalog (E) Table S1 in the electronic supplement to this paper) have an average cross-correlation value of 0.87 , with good amplitude ratios, and are improved (i.e., increased variance reduction) yet consistent with longer period solutions from the Global Centroid Moment Tensor (CMT) catalog.
\end{abstract}

Online Material: Table of 184 event solutions from 3D moment tensor inversion.

Introduction

The ability to obtain reliable earthquake source solutions is a useful tool to any tectonic interpretation. Source mechanisms prove invaluable in the assessment of plate motions, accurate characterizations of faults, and defining regional stresses. Holt et al. (1991) showed how moment tensors (MTs) can be related to the seismically released strain rate, allowing an estimate of the regional tectonic strain rate. Strain rates calculated from earthquake MTs can aid in the evaluation of current Global Positioning System (GPS) velocity fields, as well as an evaluation of hypotheses explaining regional tectonic framework. Obtaining accurate source depths and quantifying their uncertainty is an invaluable source of information providing an additional constraint on plate motions, especially in a region of complex geology with multiple emergent subduction zones, complex fold-andthrust belts, and thickened crust.

Furthermore, accurate source parameters are necessary for the improvement of 3D Earth models in full-waveform inversion methods. The use of full waveforms requires well-constrained source parameters to avoid mapping source errors into updated Earth models, as well as maximizing the number of measurements in the full-waveform inversions (Zhao et al., 2005; Maggi et al., 2009; Tape et al., 2009).

We solve for source solutions using a full-waveform MT methodology computed using synthetic seismograms from both 1D and 3D tomographic models at two frequency bands. With each inversion we compute a variance reduction from the initial solution, assess the goodness of fit between the data and synthetic seismograms, and determine the stability of each event solution. A quantitative comparison of each inversion case allows for an assessment of the advantages and limitations of different seismological techniques using similar data sets.

\section{Geologic Setting}

Our study region is geographically broad and tectonically diverse, spanning nearly the entire Middle East, parts 
of western Asia, and northern Africa. It can be broken into seven broad tectonic regions (Fig. 1): (1) Zagros mountain range; (2) Makran subduction zone; (3) Iranian plateau; (4) Caspian basin and the surrounding ranges of the Alborz, Kopet Dagh, and Talesh mountains; (5) Caucasus; (6) the Arabian plateau in Saudi Arabia; and (7) Hindu Kush/Tian Shan to the east. The combination of convergence between the Arabian and Eurasian plates in the west and India's collision with Eurasia in the east has created a complex area of intercontinental mountain belts, deep basins, incipient subduction, and dynamic microplates.

Motion of the Eurasian and Arabian plates led to the closure of the Neo-Tethyan Ocean during the late Neogene, with the onset of collision between Arabia and Eurasia occurring between 35-23 Ma (Vernant et al., 2004; Adams et al., 2009; Hatzfeld and Molnar, 2010). Intracontinental shortening accommodates most of the convergence, especially in Iran; however, large strike-slip faulting occurs along block margins. The interplay between strike-slip and thrusting motion results in compressional structures that strike obliquely, relative to the regional convergence direction (Vernant et al., 2004). The transition zone between strike-slip motion in the Zagros mountain range (on the Main Recent fault and North Anatolian fault) and the Makran subduction zone is marked by large strike-slip motion on the MinabZendan-Palami fault (Vernant et al., 2004). The best estimates for the current motion between Arabia and Eurasia is between 18 and $25 \mathrm{~mm} / \mathrm{yr}$, which is slightly slower than the precollision rate of $31 \mathrm{~mm} / \mathrm{yr}$ (Hatzfeld and Molnar, 2010). Roughly $20 \%$ of Arabia-Eurasian convergence is accommodated for in the Zagros (Hatzfeld and Molnar, 2010).

To the east, the Hindu Kush and Tian Shan ranges reflect the transmission of stresses north, due to the collision of the Indian subcontinent into Eurasia, beginning roughly during the Tertiary period (55-45 Ma) (Hatzfeld and Molnar, 2010). Similarly to Arabia's collision with Eurasia, the rate of convergence decreased rapidly after the plates collided; Hatzfeld and Molnar (2010) cite a precollision rate of $110 \mathrm{~mm} / \mathrm{yr}$ compared with a present rate of 32-44 mm/yr. Reigber et al. (2001), using GPS, quantify nearly $20 \mathrm{~mm} / \mathrm{yr}$ of deformation accommodated for within the Tian Shan alone. A better understanding of the complex motion between microplates and macroplates in the region is needed to unravel the tectonic history and structure.

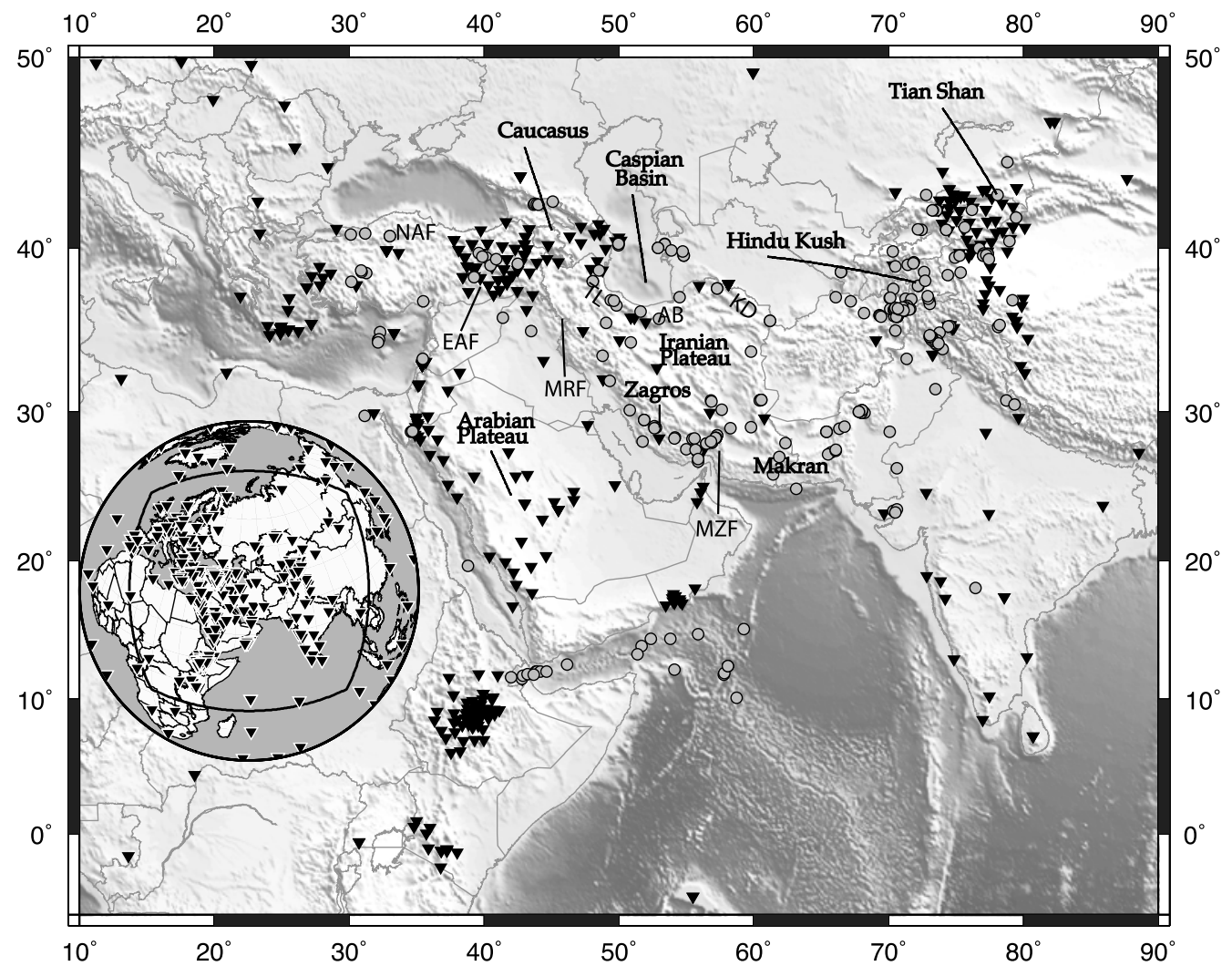

Figure 1. Events (circles) and stations (triangles) used for this study within the Middle East. Inset shows the global distribution of $\sim 580$ stations used with the 3D S2.9EA wave-speed model. Synthetic seismograms were created using the specfem3d software package and calculated for all stations located within the $90^{\circ} \times 90^{\circ}$ mesh (black box). Major faults and mountain ranges discussed in the paper have been labeled: North Anatolian fault (NAF); East Anatolian fault (EAF); Main Recent fault (MRF); Minab-Zendan-Palami fault (MZF); Talesh (TL), Alborz (AB), and Kopet Dagh (KD) mountain ranges. 


\section{Moment Tensor Inversion Methodology}

\section{Data Set}

An original earthquake event list, obtained from the Global Centroid Moment Tensor (Global CMT) catalog (Dziewonski et al., 1981), was compiled containing events between January 1990 and July 2007; events with a moment magnitude greater than or equal to 5.5 were used. This list contained more than 200 events within the study region, spanning the Middle East west-east from Turkey to India $\left(30^{\circ}-80^{\circ} \mathrm{E}\right)$ and the Horn of Africa south-north to the Kazakh Platform $\left(10^{\circ}-50^{\circ} \mathrm{N}\right)$ (Fig. 1). Broadband seismic waveform data were acquired from IRIS Data Management Center (DMC) regional and teleseismic stations; a total of 578 stations from 21 receiver networks were used for the MT inversions. Typical source-to-station distances ranged from a couple hundred kilometers to $90^{\circ}$.

\section{Inversion}

We follow an MT inversion methodology by Liu et al. (2004), adapted from a local to regional set of earthquakes, and solve for the six independent seismic MT elements $\left(M_{i j}\right)$ plus the event depth. We perform inversions for constrained, zero-trace and double-couple, and unconstrained solutions, azimuthally weighted and unweighted, with and without depth variation. The variety of inversion parameterizations was done to assess the stability of each solution and the robustness of the inversion method; then we compared the results using different constraints to determine a robust solution. As in Liu et al. (2004), a comparison of the solutions from different parameterizations showed little difference among the solutions driven by the large number of measurement windows and the stability of the method; our focal mechanism solutions remain consistent for each case. A zero-trace, azimuthally weighted solution while solving for depth is used for error-analysis comparisons between wave-speed models and frequencies, as this parameterization produced a robust solution with good match between the data and synthetics. Our methodology lends itself to testing the source of non-double-couple components by comparing solutions between models of 1D wave speed and 3D wave speed to investigate whether a reduction in misfit reflects imperfections in the model, as suggested by Liu et al. (2004). If the source of the non-double-couple component is indeed an effect of a poorly constrained Earth structure in the model, we should see a reduction in the non-doublecouple component going from 1D to 3D parameterizations.

We define the misfit objective function, $E$, as in Liu et al. (2004) where

$$
E\left(m, \mu_{1}, \mu_{2}\right)=\lambda E_{1}(m)+\mu_{1} C_{1}(m)+\mu_{2} C_{2}(m) .
$$

$E_{1}$ represents the least-squares misfit function

$$
E_{1}(m)=\frac{1}{2 A_{1}} \sum_{i=1}^{N} w_{i} \int\left[d_{i}(t)-s_{i}(t, m)\right]^{2} d t .
$$

$C_{1}(m)$ is a zero-trace MT constraint, $C_{2}(m)$ is a doublecouple source mechanism constraint, $\lambda$ is the function weight, and $\mu_{1}$ and $\mu_{2}$ are Lagrange multipliers associated with the constraints; in equation (2) $A_{1}$ is a normalization factor, $w_{i}$ represents specified weights (e.g., azimuthally weighted, $\left.w_{i}^{a}\right), d_{i}$ and $s_{i}$ are the data and synthetics, respectively, and $m$ is the MT. Synthetics are allowed to shift in time to match data.

\section{Synthetic Seismogram Generation}

Full-waveform synthetic seismograms are required for the MT inversion. We computed both 1D and 3D synthetics to compare wave-speed models independent of the inversion methodology. One-dimensional synthetics were created using mode summation from the preliminary reference Earth model (PREM; Dziewonski and Anderson, 1981) wavespeed model. Synthetics for the 3D reference model case were created using the spectral-element method (SEM; Komatitsch and Tromp, 1999, 2002a, 2002b) using the S2.9EA (Kustowski et al., 2008) wave-speed model. Benefits and details of using the SEM methodology over other methodologies are described in Komatitsch and Tromp (1999, (2002a, b). The cost for computation of the 3D synthetic seismograms was significant but tractable on a dedicated cluster. The S2.9EA model is a global shear-wave velocity structure model based on the PREM reference and determined from surface-wave phase velocities, longperiod waveforms, and body-wave travel times (Kustowski et al., 2008). The full 3D wave-speed model also uses a CRUST 2.0 crustal model (Bassin et al., 2000), attenuation from PREM (Dziewonski and Anderson, 1981), and ETOPO5 topography/bathymetry (NOAA, 1988). Compressional wave-speed perturbations are scaled from shear-wave-speed perturbations by 0.55 as in Kustowski et al. (2008). Initial MT solutions were obtained from the Global CMT catalog (Dziewonski et al., 1981).

Synthetic seismograms and Fréchet derivatives for each component of the MT and depth were created at all stations within a $90^{\circ} \times 90^{\circ}$ mesh seen in Figure 1 (inset). The depth derivative was calculated by the difference between synthetics from the initial solution and synthetics with a depth increased by $d h$. Based on synthetic tests, depth perturbations of $1,10,15,20,25$, and $50 \mathrm{~km}$ show less than a $1 \%$ change in calculated depth derivatives for all perturbations, with the exception at $50 \mathrm{~km}$, which is an unreasonable $d h$-value for shallow events. We use a $d h$-value of $1 \mathrm{~km}$.

\section{Data Processing}

Data were filtered between $25 \mathrm{~s}$ and $125 \mathrm{~s}$ (short period) and $60 \mathrm{~s}$ and $125 \mathrm{~s}$ (long period) to compare the inversion performance and results at different period bands; a maximum frequency of $125 \mathrm{~s}$ was used due to band limitations in instrument response. A bootstrap analysis was computed to assess solution robustness (Press et al., 

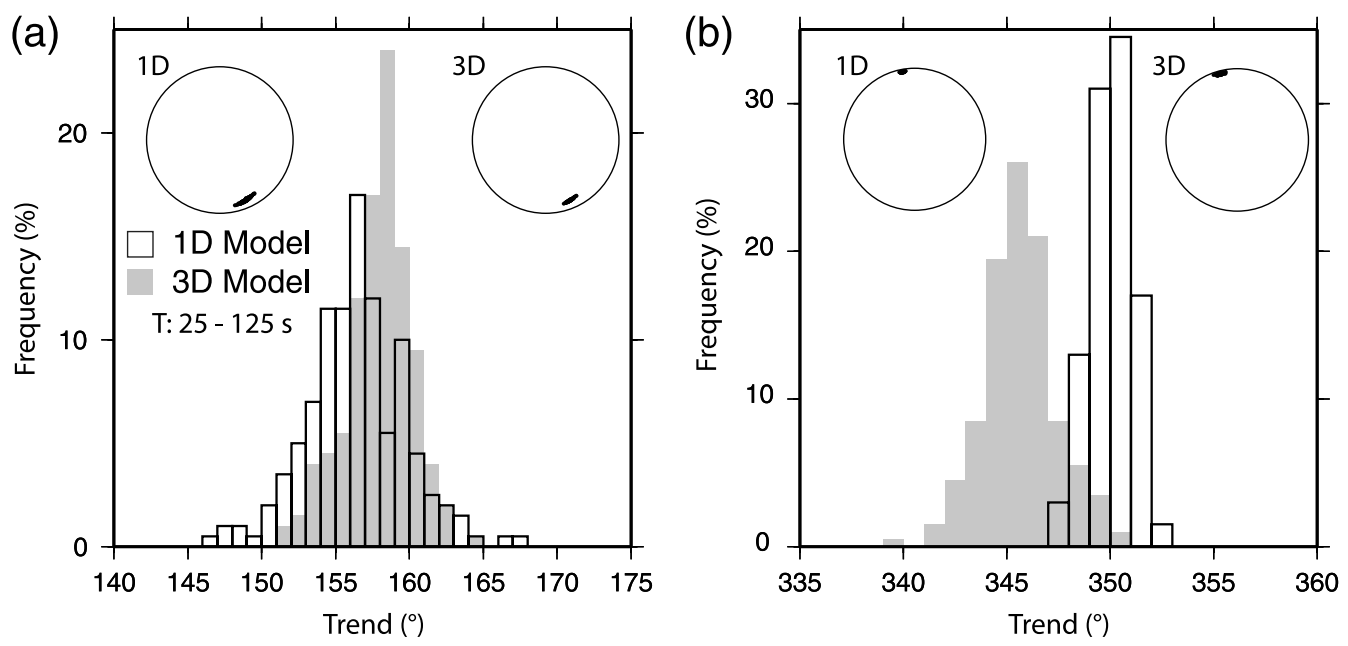

Figure 2. Results of a bootstrap statistical analysis for two single events: (a) 13 May 1997 and (b) 22 February 2005. Plotted in the upper left and right are the $P$ axes on a focal sphere after each inversion $(n=200)$ using 1D and 3D models. A tighter cluster of dots indicates a more constrained solution and a smaller standard error on the $P$ axes of the solution. The histogram shows the distribution of results for the trend $(n=200)$ for each particular event.

1997). During the bootstrap analysis, we solved for each event solution 200 times using a random selection of components (radial, vertical, and tangential) from the original data set. The $P$ axes were then plotted on a focal sphere to quantitatively assess the stability of the plunge and trend (see Fig. 2).

The Flexwin (Maggi et al., 2009) algorithm was used to automatically select time windows for input into the MT inversion using a combination of criteria based on phase, amplitude, ratio of short-term and long-term average, and envelope mismatch. Flexwin allows for a large volume of repeatable measurements on full-waveform data-synthetic pairs that would otherwise be overlooked when hand-picking only peaks for specific phases or amplitudes. Flexwin has user-tunable parameters and the ability to adapt to 1D and 3D models (Maggi et al., 2009). Applying the user-tunable parameters detailed in Maggi et al. (2009), we required a cross-correlation value of 0.75 and an amplitude ratio (dlnA) of $<1.0$ for Flexwin windows to be accepted in the MT inversion. A minimum signal-to-noise ratio of 3.5 within two measurement windows, and a minimum single window signal-to-noise ratio of 1.5 , were required to use the time series in the MT inversion. Flexwin fine-tuning parameters are $c_{0}=0.7, c_{1}=4.0, c_{2}=0.0, c_{3 a, b}=(1.0,2.0)$, and $c_{4 a, b}=(3.0,10.0)$ (see Maggi et al., 2009 for details). A consistent number of evaluation windows was used for each inversion case, permitting an appropriate comparison without bias to the amount of waveforms being evaluated (Table 1).

\section{Moment Tensor Inversion Results}

We recovered 184 well-constrained solutions out of the initial set of events (for the complete earthquake catalog, (E) see Table S1 in the supplement); the remaining 11 events had data quality issues that did not produce acceptable results. The average constraint on the trend and plunge is shown as a histogram in Figures 2 and 3 and in Table 1. Standard errors were determined for the trend and plunge of the MT compressional axes, $P$ axes, using the bootstrap methodology discussed previously. Standard errors for the trend and plunge of the $T$ axes were also analyzed; the errors are comparable to the spreads for the $P$ axes, and as such we do not report results for the $T$ axes.

\section{Comparison}

To quantify the effect of the wave-speed model on the MT inversion, comparisons were made between 1D and 3D MT solutions using an identical data processing scheme and a consistent number of evaluation windows; this allows for direct comparisons of inversion results based on wave-speed models and frequency bandwidth without bias to methodology or the number of evaluation windows. The 1D wavespeed model does a sufficient job fitting simple body-wave signals and large-amplitude surface waves at both period bands (see example waveforms in Fig. 4). Complex signals, from body-wave propagation and surface-wave dispersion due to the continental lithosphere, are not adequately fit by the 1D model at shorter periods. Employing the 3D wavespeed model (Kustowski et al., 2008), synthetic seismograms predict a larger portion of the data at all periods, including the late-arriving shorter period arrivals due to strong dispersion from the continental lithosphere. Additionally, using an appropriate 3D model improves the amplitude and phase misfits when compared with a 1D model and facilitates the use of more waveform data in the MT inversion.

A quantitative comparison of the variance reduction between 1D and 3D models shows that, within the same frequency band, a reduction in error on the trend and plunge is 
(a)

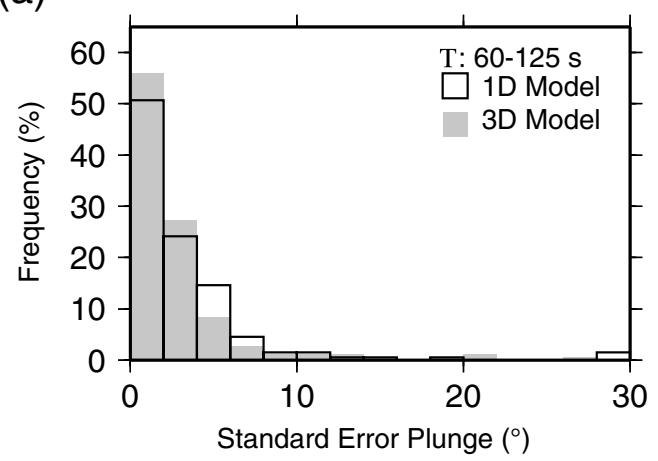

(c)

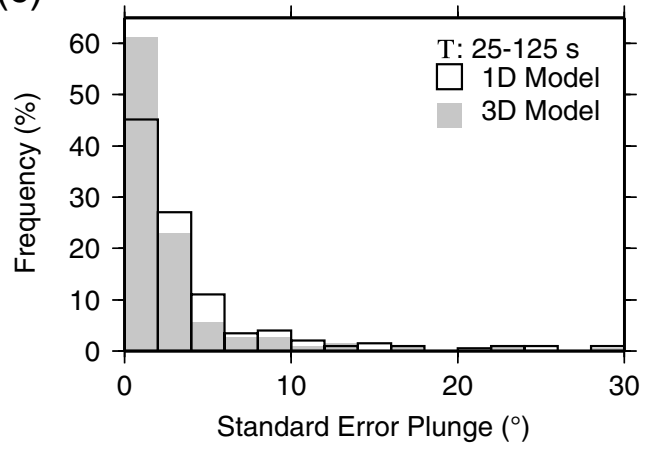

(b)

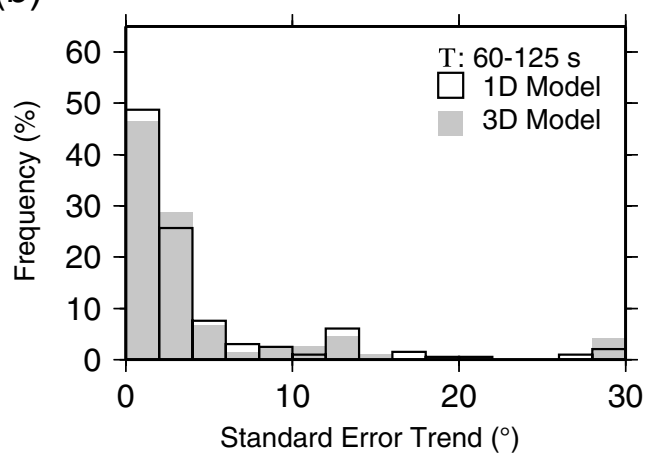

(d)

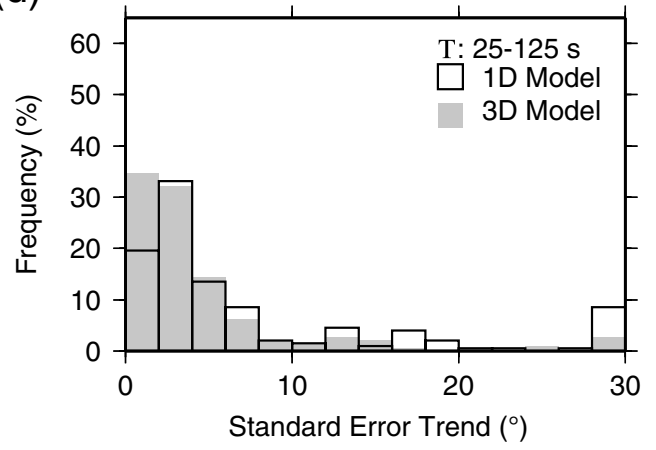

Figure 3. Moment tensor inversion standard error for all events, $n=195$. Histograms show the standard error for two frequency bands, (a,b) 60-125 s and (c,d) 25-125 s, on the trend and plunge. The last bin represents standard errors $>30^{\circ}$. Gray bars represent the use of 3D (Kustowski et al., 2008) derived synthetics. White bars represent using 1D model (Dziewonski and Anderson, 1981) derived synthetics.

seen when using the 3D model, versus the 1D model (Table 1). At longer periods, 60-125 s, the difference between using the $1 \mathrm{D}$ and 3D model is negligible, seen only as an approximate difference of $0.39^{\circ}$ on the trend and plunge. At shorter periods, 25-125 s, the improvement is more significant, reducing the error by approximately $4.43^{\circ}$ on the trend and $1.34^{\circ}$ on the plunge (see Fig. 3).

A metric was created to ease the comparison between inversion runs by defining a variable $\tau$ as

$$
\tau=\lambda_{1} \overline{|1-C C|}+\lambda_{2} \overline{|\Delta \ln A|}+\lambda_{3} \overline{|\xi|}-\lambda_{4} \frac{N}{200}+\lambda_{5} \frac{A Z}{360},
$$

where $\lambda_{1-5}$ represents the relative weights $\left(\lambda_{1}=5, \lambda_{2}=\right.$ $\left.0.25, \lambda_{3}=1, \lambda_{4}=0.05, \lambda_{5}=0.05\right) ; \overline{C C}$ is the average cross-correlation value; $\overline{\Delta \ln A}$ is the average amplitude ratio; $\bar{\xi}$ is the average misfit; $N$ is the number of windows used; and $A Z$ is the maximum azimuthal gap. Weights were chosen to emphasize the importance of the cross correlation, $\overline{C C}$, and

Table 1

Comparison between 1D and 3D Inversion Sets*

\begin{tabular}{lcccc}
\hline & $1 \mathrm{D}$ at $60 \mathrm{~s}$ & $1 \mathrm{D}$ at $25 \mathrm{~s}$ & $3 \mathrm{D}$ at $60 \mathrm{~s}$ & $3 \mathrm{D}$ at $25 \mathrm{~s}$ \\
\hline Trend $\left(^{\circ}\right)$ & $4.71 \pm 8.08$ & $9.66 \pm 15.95$ & $5.10 \pm 9.37$ & $5.23 \pm 9.18$ \\
Plunge $\left(^{\circ}\right)$ & $3.22 \pm 4.69$ & $4.33 \pm 8.69$ & $2.83 \pm 4.37$ & $2.99 \pm 5.65$ \\
Average cross correlation & 0.92 & 0.82 & 0.93 & 0.87 \\
Average dlnA & 0.16 & 0.41 & 0.16 & 0.37 \\
Average number of windows & 387.07 & 338.53 & 267.71 & 363.99 \\
Mean $\tau$ & $1.07 \pm 1.26$ & $1.96 \pm 1.22$ & $1.11 \pm 1.59$ & $1.52 \pm 1.25$ \\
Variance reduction mean \% & 20.12 & 24.17 & 33.42 & 36.77 \\
\end{tabular}

* Standard error on the trend and plunge of the $P$ axes for all events is calculated from the results of a bootstrap analysis; standard error of the $T$ axes shows a comparable spread and is not reported. Also shown is the result of calculating the average and standard deviation of $\tau$ from equation (3) for each inversion set. A full data set, mean reduction in variance between the data and misfit between the initial solution, $M_{0}$ solution, and our calculated solution is shown. 
$1997 / 05 / 13$

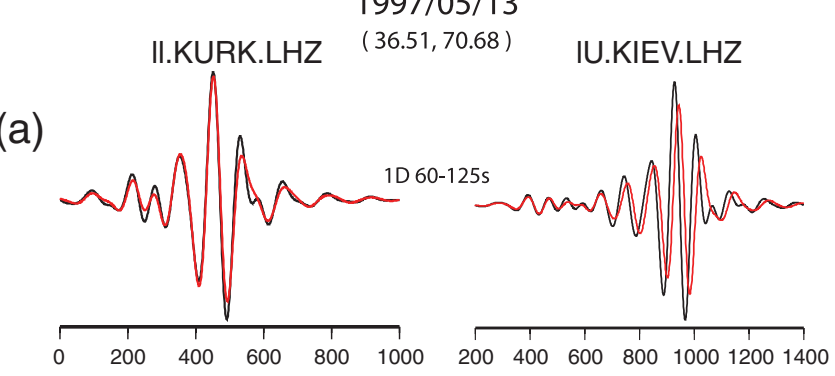

(b)

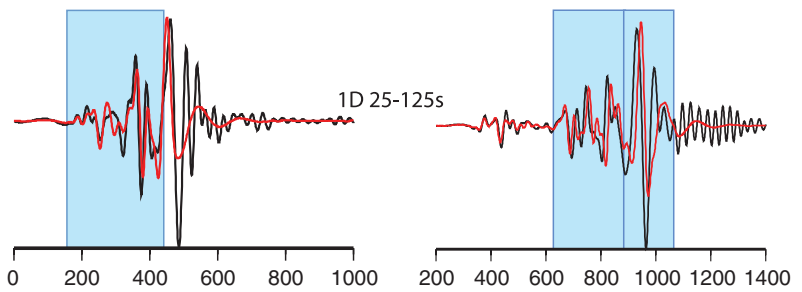

(c)

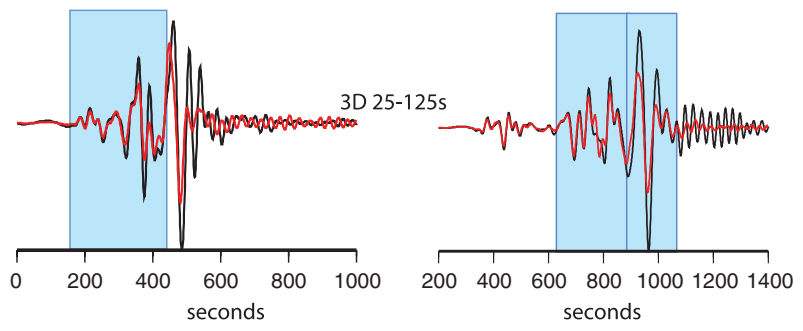

(d)

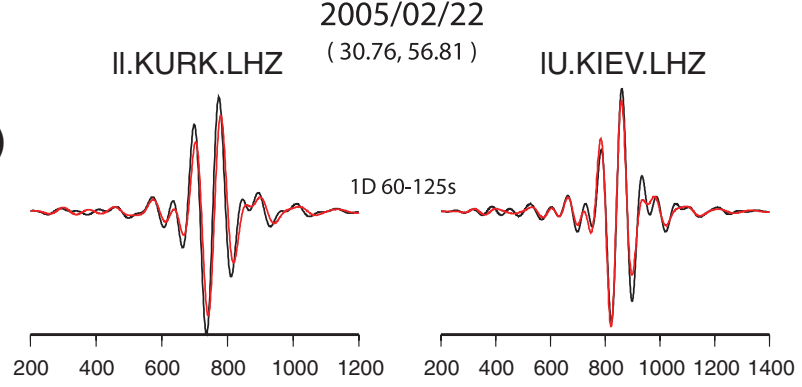

(e)

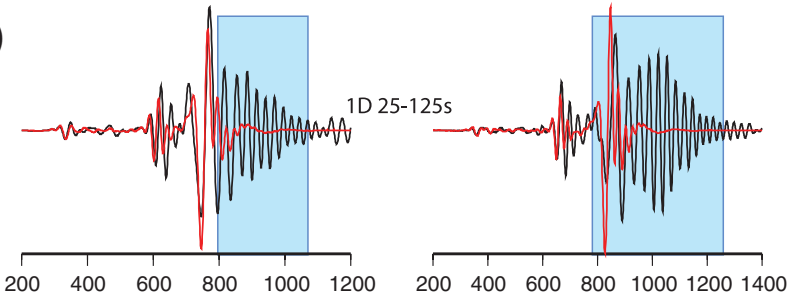

(f)

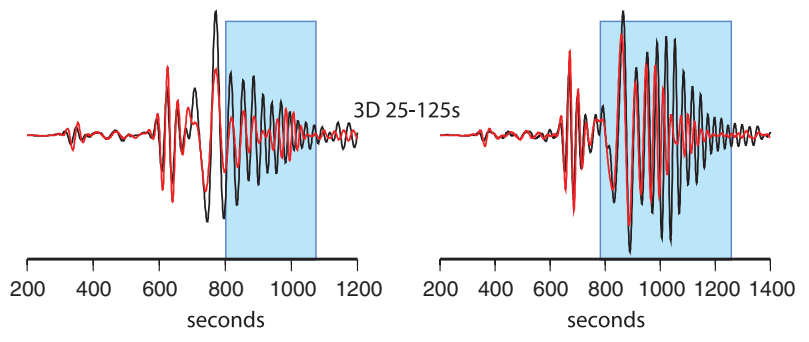

Figure 4. Displacement data (black) and synthetic (red) fit for the LHZ component shown at two stations, II.KURK (left) and IU.KIEV (right), for events (a,b,c) 13 May 1997 14:13:45.740 and (d,e,f) 22 February 2005 02:25:22920 filtered at 60-125 s and 25-125 s, and inverted using 1D (Dziewonski and Anderson, 1981) and 3D (Kustowski et al., 2008) wave-speed models. Event locations are indicated (latitude, longitude) beneath the event date. A better fit to the data is seen for complex body waves between $150-450 \mathrm{~s}$ for II.KURK and $600-900 \mathrm{~s}$ for station KIEV, as well as surface-wave dispersion at greater than $800 \mathrm{~s}$ when using the 3D derived synthetic seismograms (highlighted by the blue box).

misfit, $\bar{\xi}$, to the goodness of fit, and downweight the larger numbers associated with the $N$ and $A Z$ variables. Based on this defined metric, where a smaller $\tau$ value indicates better goodness of fit, $95 \%$ of the events have $\tau$ values $<10$, and $85 \%-90 \%$ have $\tau$ values ranging between 0 and 2 . We calculate the mean $\tau$ and standard deviation for each inversion set (1D at $25 \mathrm{~s}, 1 \mathrm{D}$ at $60 \mathrm{~s}, 3 \mathrm{D}$ at $25 \mathrm{~s}, 3 \mathrm{D}$ at $60 \mathrm{~s}$ ) to obtain a single number with which to evaluate the entire data set. Events with metric values $\tau>10$ are considered to be very poorly fit and are not included in the inversion set averages. Typically, an event with a large metric, or poor goodness of fit has severe data quality, or lack of data issues, resulting in values of $\tau>>100$.

Based on trend and plunge standard error improvements, increases in the cross-correlation coefficient, and variance reduction for short periods (25-125 s; see Table 1 and Figs. 3 and 4), the 3D S2.9EA model (Kustowski et al., 2008) produces a better fit to the data than the 1D PREM (Dziewonski and Anderson, 1981). At shorter periods waveform fit deteriorates slightly, relative to the longer period data ( $60 \mathrm{~s}$ versus $25 \mathrm{~s}$ ), as seen by the decrease in cross-correlation value and increase in the mean $\tau$ (Table 1); however, the benefit is the incorporation of much more seismic data into the source inversion as a result of 3D synthetics predicting a larger portion of the waveform data (Fig. 4).

Results compare favorably with previously published solutions in both mechanism and depth (Jackson et al., 2002; Talebian and Jackson, 2004; Tatar et al., 2004), as well as the Global CMT solutions. Figure 5 shows a comparison between the Global CMT solutions for three events and our calculated solutions. For each event, our calculated source mechanisms are similar to the Global CMT.

Depth

Comparison of our revised depth versus the Global CMT depths is made in Figure 6. Differences between 1D and 3D wave-speed models are subtle, yet present, especially for shallow events. Agreement between our determined depths and those from the Global CMT improves with the inclusion of shorter period data (25-125 s); this is especially true at shallow depths. Lack of Global CMT event depths less than $15 \mathrm{~km}$ is a result of a constraint imposed on their solution; our inversions do not impose this constraint. A cluster of events between a depth of 50 and $150 \mathrm{~km}$ is in agreement with Global CMT, with the inclusion of shorter periods. For deep events $(>200 \mathrm{~km})$ a systematic divergence exists 
(a)

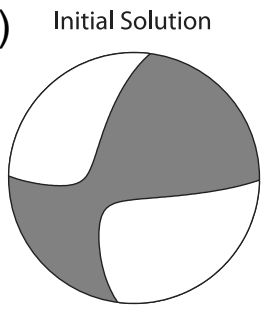

(c)

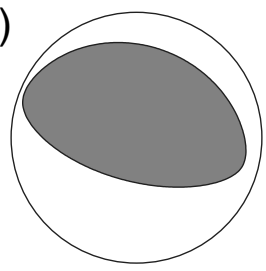

(e)

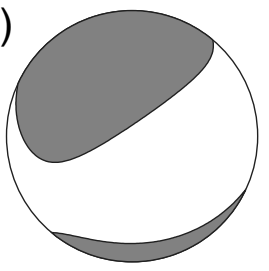

(b)

2007/01/08

17:21:49.910

$22.36 \%$

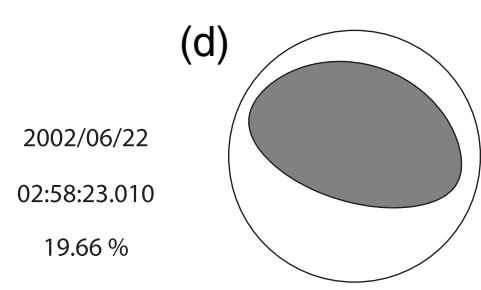

$2000 / 05 / 12$

23:10:29.980

$15.10 \%$ (f)

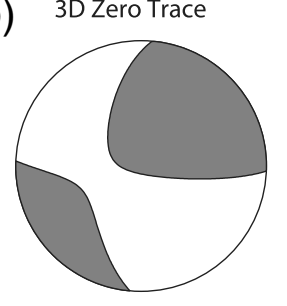

(d)

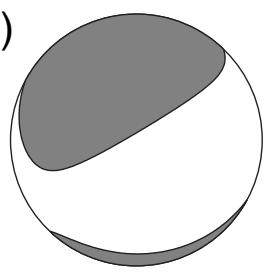

Figure 5. (a,c,e) Comparison between the Global CMT solution and $(b, d, f) 3 D$ azimuthally weighted seven-parameter solution. Our solutions compare well with the initial solution, but variance between the data and synthetic is reduced while fitting more of the data using a 3D model. Percentage represents the variance reduction between our solutions and the Global CMT solution. A majority of events in the catalog (E) see Table S1 in the supplement) see a variance reduction between $5 \%$ and $40 \%$ compared with the Global CMT solution.

between our solutions and those from the Global CMT because the calculated depth is shallower than the initial depth; this is most likely due to S2.9EA's heterogeneous wave speeds at depth. Additionally, Muyzert and Snieder (1996) have shown that these large deviations in the depth may

possibly be due to unstable initial phase behavior in the long-period surface waves.

\section{Discussion}

The comparison between the Global CMT solutions and the MT solutions presented here show minimal difference in source mechanism, an average of $7.31^{\circ}$ and $7.56^{\circ}$ difference for the $P$ and $T$ axes, respectively, for the 3D 25-125 s case. This is true for all four cases examined (1D versus 3D model, minimum period $25 \mathrm{~s}$ versus $60 \mathrm{~s}$ ) and when varying constraints were applied to the inversion. In all cases, a reduction in variance between data and synthetic is seen between the original solution and our calculated solutions. The greatest reduction in variance is seen in the 3D case when filtered between $25 \mathrm{~s}$ and $125 \mathrm{~s}$ shown in Table 1. A majority of events see a variance reduction of 5\%-40\%, which represents a significant improvement in fitting waveforms. Events with the largest variance reduction are a result of a better amplitude agreement between the data and synthetic.

The largest contribution to the misfit in our result can be attributed to poorly constrained shallow Earth structure in our models. The use of shorter periods (25-125 s) introduces a potential for contamination from larger errors due to unresolved wave-speed structures. At shorter periods, Earth structure will have a greater influence on the propagating wavefield, and errors in the Earth model may be mapped into the source solution. There is a small, but significant increase in standard error on the trend and plunge, as well as a decrease in the average cross-correlation value from 60-125 s to $25-125 \mathrm{~s}$ (Table 1). We do not feel the degradation in solution stability, as seen by the increase in trend and plunge standard error, and waveform metrics, as seen by the decrease in the cross-correlation value, are justification for the removal of shorter period signals. Alternatively, the addition of shorter period signals, 25-125 s, allows for much
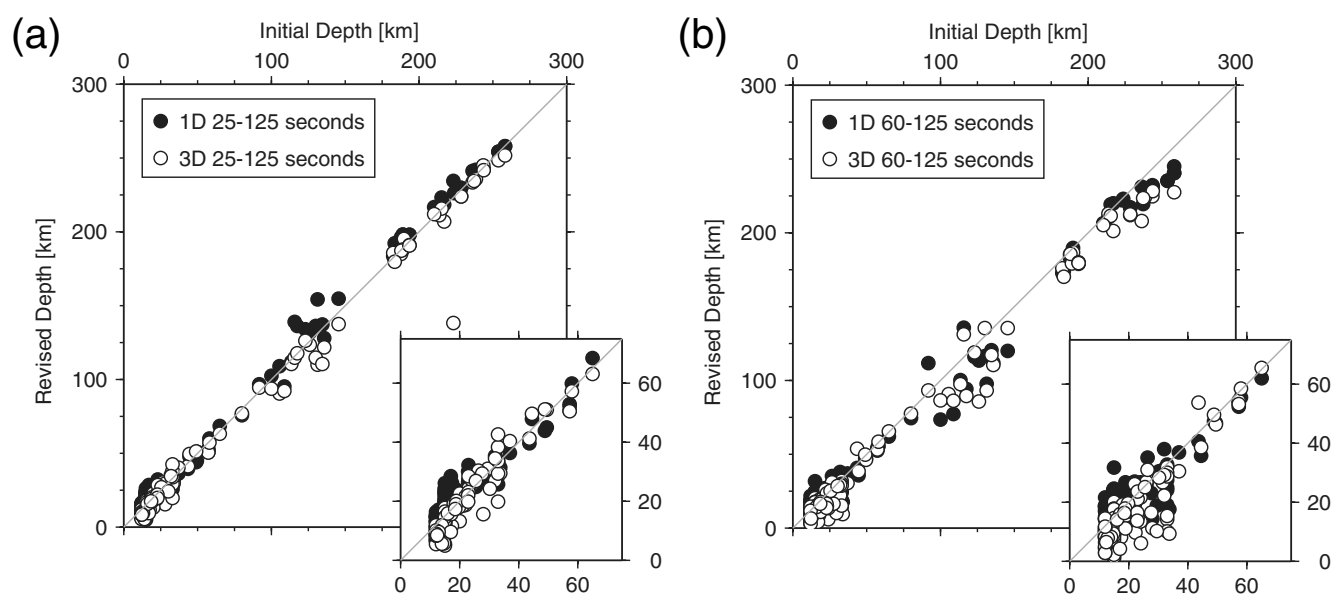

Figure 6. Original Global CMT depth (initial depth) plotted against this study's depths (revised depth) from the zero-trace azimuthally weighted solution; the line represents a 1-1 relationship between the 1D and 3D depth solutions. (a) Short period (25-125 s) solutions have a tighter fit to the 1-1 line than do (b) longer period (60-125 s) solutions. Insets show results at shallow depths. Depth residuals are smaller than symbol size (average residual is less than $2.5 \mathrm{~km}$ ) and therefore are not plotted. 


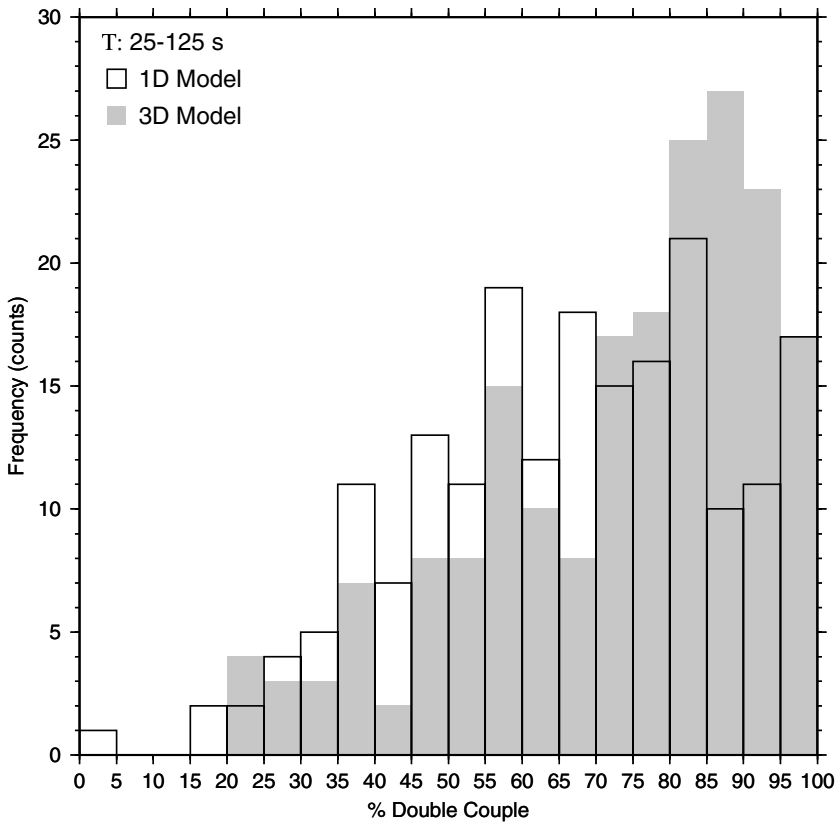

Figure 7. Histogram showing the percentage double-couple component for short period (25-100 s) solutions. A larger percentage double couple is seen when using 3D-derived synthetic seismograms (gray) compared with 1D-derived synthetics (white). This result provides evidence that the percentage of non-double-couple components in the solutions is a result of imperfect and poorly resolved Earth structure within the initial velocity models.

more seismic data to be incorporated into the inversion, as seen by an increase in the number of evaluation windows from the 1D model at $25 \mathrm{~s}$ to the 3D model at $25 \mathrm{~s}$ (Table 1), indicating a robust predictive capability of the $3 \mathrm{D}$ wavespeed model over a wide period range. An azimuthal gap in seismic stations seen in Kazakhstan and Russia also contributes to the error of the trend of some solutions, but for most events the overall azimuthal coverage is excellent and the trend is well constrained for the entire data set as a whole when using the 3D MT inversion.

The percentage of double couple, defined by decomposing the MT into a double-couple and CLVD component (Stein and Wysession, 2009), increases when using a 3D model relative to the $1 \mathrm{D}$ model results, implying the non-doublecouple component of the solution comes from poorly constrained wave-speed structure in the 1D model relative to the 3D model. The nature of observed slip on faults being both nonplanar, as in rotational faulting, and/or events with complex rupture histories, may manifest itself as volumetric change (i.e., non-double-couple) within the source (Julian et al., 1998). We plot the percentage of double-couple components in our solutions using 1D and 3D models at 25-125 s periods (Fig. 7) to test the hypothesis that nondouble-couple components are a reflection of poorly constrained regional structure in the initial velocity model or complex fault geometry, consistent with suggestions made by Liu et al. (2004) and Henry et al. (2002). The number of events in our catalog with significant non-double-couple components suggests that improvements in the wave-speed model are needed. Experiments by Hjörleifsdóttir and Ekström (2010) to evaluate source parameters using synthetic seismograms at periods greater than $40 \mathrm{~s}$, show small errors in the non-double-couple component when using a diverse seismic data set, similar to the global catalogs (Miller et al., 1998). Experiments here using real data are consistent with synthetic experiments at longer periods, but the use of a 3D wave-speed model and shorter periods, $25 \mathrm{~s}$, significantly increases the double-couple component. This may suggest a frequency dependance to resolving the non-double-couple components. At longer periods (60-125 s), not shown, the difference between 1D and 3D percentage double couple is minimal, further suggesting that 3D structure at short periods is the cause for increased double-couple component. We would expect an increase in the percentage of double-couple components in the source with improvements made to the wave-speed model; however, due to the complex nature of real faulting, a completely double-couple source is unlikely. A subset of our deepest events (100 to $\sim 260 \mathrm{~km}$ ) shows a similar trend as for the whole catalog.

\section{Tectonics}

Comparisons between our solutions with regional tectonic features show good general agreement with previous geologic interpretations (Fig. 8). Within the Zagros, rightlateral strike slip and northeast-striking convergence are dominant, corresponding to right-lateral strike-slip motion on the Main Recent fault and general northeast motion reflecting the collision of the Arabian plate with Eurasia, and consistent with tectonic interpretations made by Talebian and Jackson (2004), Tatar et al. (2004), and Hatzfeld and Molnar (2010). Northeast-striking thrust events also dominate in the Caspian basin region and Alborz mountain range as seen in Jackson et al. (2002). Two large strike-slip mechanisms, one in the Kopet Dagh region and another near the border of Iran and Afghanistan, reflect rotation around rigid blocks within central Iran (Vernant et al., 2004; Hollingsworth et al., 2006, 2008, 2009; Hatzfeld and Molnar, 2010). In Turkey large strike-slip mechanisms are consistent with motion along the North Anatolian fault and East Anatolian fault to the east. Within the Red Sea, tensile mechanisms reflect extension within the basin. Other notable trends are seen in the Gulf of Aden, where a cluster of non-double-couple strike-slip events exist. The Hindu Kush/Tian Shan regions are dominated by reverse and normal faults; the strikes vary considerably, reflecting the complexity of the regional structure and collision of the Indian subcontinent and Eurasia.

\section{Conclusions}

Using a full-waveform MT inversion method (Liu et al., 2004), we repeat an identical data processing scheme for four cases using two initial models (1D and 3D) and two 


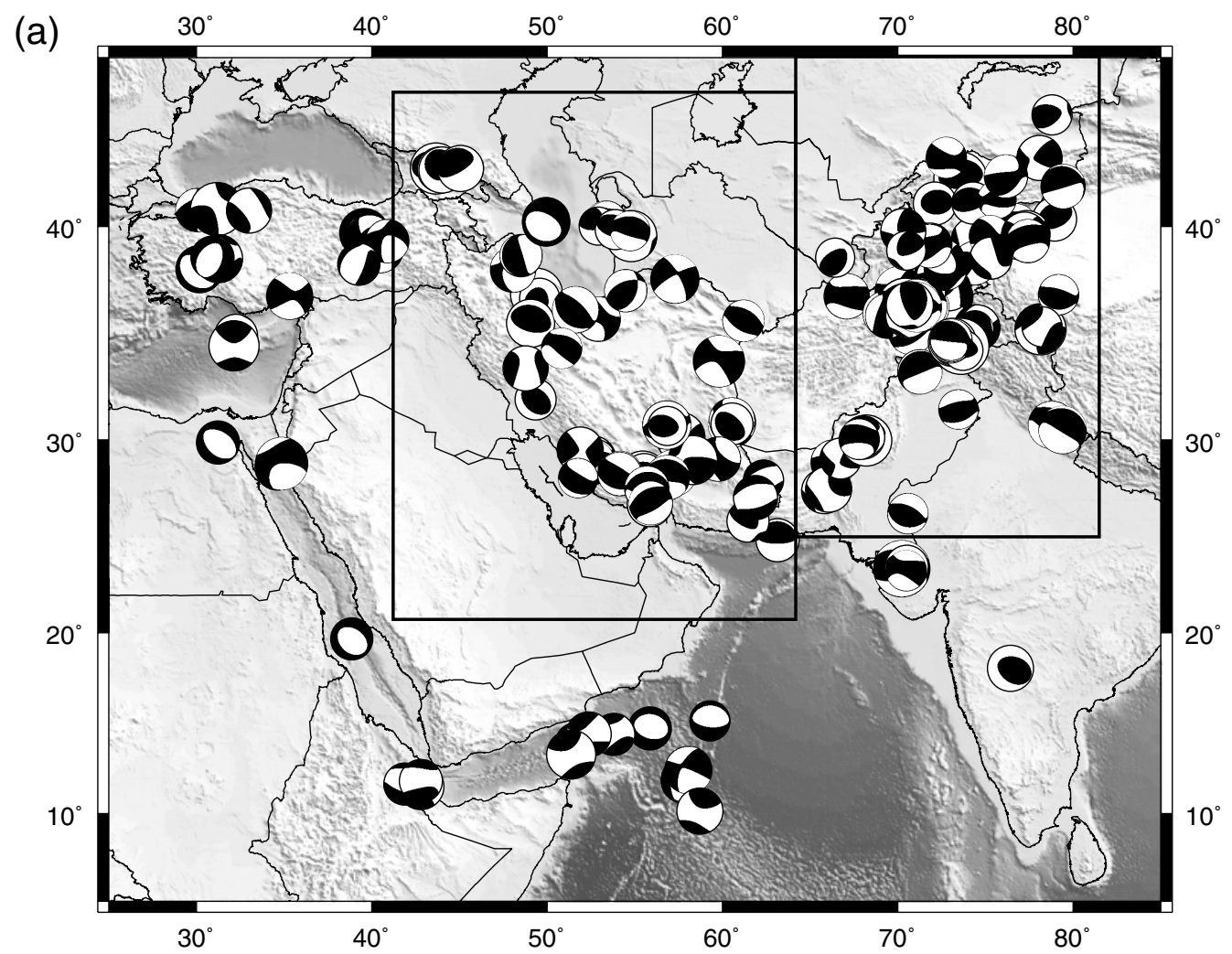

(b)

(c)
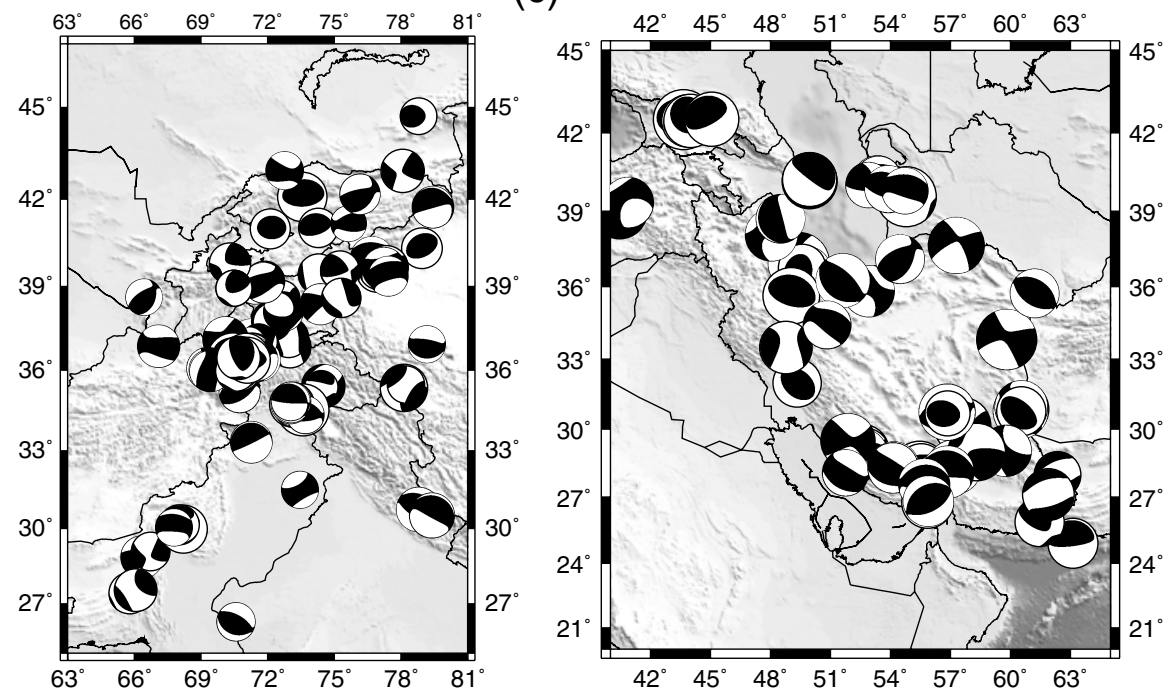

Figure 8. (a) Earthquake event solutions for the entire data set and highlighted regions, (b) Hindu Kush and Tian Shan, and (c) Iran. Shown are 195 solutions from the 3D zero-trace azimuthally weighted MT inversion. Solutions agree well with regional tectonics and large-scale plate motions.

frequency bands, allowing for direct comparison between results and the evaluation of model and frequency bandwidth. The number of evaluation windows is consistent for each inversion set, permitting an appropriate comparison between models and frequency ranges without bias given to the number of evaluations.

We provide justification for the use of 3D models over 1D models by showing a reduction in variance and better constraint on MT solutions, source characteristics, Earth structure, and event depth. This is especially true in regions of highly heterogeneous Earth structure, as seen in our study region. The 1D model does not provide an adequate fit to waveforms at shorter periods, especially to fitting complex body-wave propagation and surface-wave dispersion. Additionally, the 3D model produces a solution with a greater percentage of the source approximated as a double couple, 
suggesting that the non-double-couple component of our solutions comes from poorly constrained wave-speed structure. We achieved an overall agreement in mechanism and depth with regional tectonics across inversion methods, wave-speed models, and frequency range, confirming the stability and robustness of our methodology and solutions. Further, the solutions obtained in this study agree with those found by previous researchers, the Global CMT, and other large-scale geologic structures and overall GPS measurements (DeMets et al., 1994; Jackson et al., 2002; Tatar et al., 2004; Vernant et al., 2004; Adams et al., 2009; Hatzfeld and Molnar, 2010).

\section{Data and Resources}

The facilities of the IRIS Data Management System, specifically the IRIS Data Management Center (DMC), were used for access to waveform and metadata required in this study. The IRIS DMC is funded through the National Science Foundation, specifically the Directorate for Geosciences through the Instrumentation and Facilities Program of the National Science Foundation under Cooperative Agreement EAR-0552316. The Global CMT catalog was used to compile earthquake events by using http://www.globalcmt.org/ CMTsearch.html (last accessed May 2012). Synthetic seismogram simulations were carried out on supercomputing facilities at the University of Rhode Island and Princeton University. Map figures were produced using GMT (Wessel and Smith, 1991).

\section{Acknowledgments}

We would like to thank Qinya Liu for providing the codes to calculate our source mechanism solutions and for her helpful comments throughout the process; Daniel Peter for his help creating synthetic seismograms; and Arthur J. Rodgers, Jeroen Tromp, and Yang Shen for providing valuable insight. We would also like to thank three anonymous reviewers for their helpful comments and suggestions. This research was supported by the Air Force Research Laboratory under contract No. FA8718-08-C-0009.

\section{References}

Adams, A., R. Brazier, A. Nyblade, A. Rodgers, and A. Al-Amri (2009). Source parameters for moderate earthquakes in the Zagros Mountains with implications for the depth extent of seismicity, Bull. Seismol. Soc. Am. 99, no. 3, 2044-2049.

Bassin, C., G. Laske, and G. Masters (2000). The current limits of resolution for surface wave tomography in North America, Eos Trans. AGU 81, F897.

DeMets, C., R. Gordon, D. Argus, and S. Stein (1994). Effect of recent revisions to the geomagnetic reversal time scale on estimates of current plate motions, Geophys. Res. Lett. 21, 2191-2194.

Dziewonski, A., and D. Anderson (1981). Preliminary reference Earth model, Phys. Earth Planet. In. 25, no. 4, 297-356.

Dziewonski, A., T. Chou, and J. Woodhouse (1981). Determination of earthquake source parameters from waveform data for studies of global and regional seismicity, J. Geophys. Res. 86, no. B4, 2825-2852.

Hatzfeld, D., and P. Molnar (2010). Comparisons of the kinematics and deep structures of the Zagros and Himalaya and of the Iranian and Tibetan plateaus and geodynamic implications, Rev. Geophys. 48, no. 2, 48 pp.
Henry, C., J. Woodhouse, and S. Das (2002). Stability of earthquake moment tensor inversions: Effect of the double-couple constraint, Tectonophysics 356, no. 1-3, 115-124.

Hjörleifsdóttir, V., and G. Ekström (2010). Effects of three-dimensional earth structure on $\mathrm{cmt}$ earthquake parameters, Phys. Earth Planet. In. 179, no. 3-4, 178-190.

Hollingsworth, J., J. Jackson, R. Walker, M. Gheitanchi, and M. Bolourchi (2006). Strike-slip faulting, rotation, and along-strike elongation in the Kopeh Dagh mountains, NE Iran, Geophys. J. Int. 166, no. 3, 1161-1177.

Hollingsworth, J., J. Jackson, R. Walker, and H. Nazari (2008). Extrusion tectonics and subduction in the eastern South Caspian region since $10 \mathrm{Ma}$, Geology 36, no. 10, 763-766.

Hollingsworth, J., J. Jackson, R. Walker, and H. Nazari (2009). Extrusion tectonics and subduction in the eastern South Caspian region since 10 Ma: Reply, Geology 37, no. 12, e199-e200.

Holt, W., J. Ni, T. Wallace, and A. Haines (1991). The active tectonics of the eastern Himalayan syntaxis and surrounding regions, J. Geophys. Res. $B$ Solid Earth Planets 96, no. B9, 14,595-14,632.

Jackson, J., K. Priestley, M. Allen, and M. Berberian (2002). Active tectonics of the South Caspian basin, Geophys. J. Int. 148, no. 2, 214-245.

Julian, B., A. Miller, and G. Foulger (1998). Non-double-couple earthquakes 1. theory, Rev. Geophys. 36, no. 4, 525-549.

Komatitsch, D., and J. Tromp (1999). Introduction to the spectral element method for three-dimensional seismic wave propagation, Geophys. $J$. Int. 139, no. 3, 806-822.

Komatitsch, D., and J. Tromp (2002a). Spectral-element simulations of global seismic wave propagation-I. Validation, Geophys. J. Int. 149, no. $2,390-412$

Komatitsch, D., and J. Tromp (2002b). Spectral-element simulations of global seismic wave propagation-II. Three-dimensional models, oceans, rotation and self-gravitation, Geophys. J. Int. 150, no. 1, 303-318.

Kustowski, B., G. Ekström, and A. Dziewonski (2008). The shear-wave velocity structure in the upper mantle beneath Eurasia, Geophys. J. Int. 174, no. 3, 978-992.

Liu, Q., J. Polet, D. Komatitsch, and J. Tromp (2004). Spectral-element moment tensor inversions for earthquakes in southern California, Bull. Seismol. Soc. Am. 94, no. 5, 1748-1761.

Maggi, A., C. Tape, M. Chen, D. Chao, and J. Tromp (2009). An automated time-window selection algorithm for seismic tomography, Geophys. J. Int. 178, no. 1, 257-281.

Miller, A., G. Foulger, and B. Julian (1998). Non-double-couple earthquakes. 2. Observations, Rev. Geophys. 36, no. 4, 551-568.

Muyzert, E., and R. Snieder (1996). The influence of errors in source parameters on phase velocity measurements of surface waves, Bull. Seismol. Soc. Am. 86, no. 6, 1863-1872.

NOAA (1988). Digital relief of the surface of the Earth, NOAA National Geophysical Data Center Data Announcement 88-MGG-02, National Oceanic and Atmospheric Administration, National Geophysical Data Center, Boulder, Colorado.

Press, W., S. Teukolsky, W. T. Vetterling, and B. P. Flannery (1997). Numerical Recipes in C: The Art of Scientific Computing, Second Ed., Cambridge University Press, New York, 691-692.

Reigber, C., G. Michel, R. Galas, D. Angermann, J. Klotz, J. Chen, A. Papschev, R. Arslanov, V. Tzurkov, and M. Ishanov (2001). New space geodetic constraints on the distribution of deformation in Central Asia, Earth Planet. Sci. Lett. 191, no. 1-2, 157-165.

Stein, S., and M. Wysession (2009). An Introduction to Seismology, Earthquakes, and Earth Structure, Blackwell Publishing, Malden, Massachusetts, $512 \mathrm{pp}$.

Talebian, M., and J. Jackson (2004). A reappraisal of earthquake focal mechanisms and active shortening in the Zagros mountains of Iran, Geophys. J. Int. 156, no. 3, 506-526.

Tape, C., Q. Liu, A. Maggi, and J. Tromp (2009). Adjoint tomography of the Southern California crust, Science 325, no. 5943, 988-992. 
Tatar, M., D. Hatzfeld, and M. Ghafory-Ashtiany (2004). Tectonics of the Central Zagros (Iran) deduced from microearthquake seismicity, Geophys. J. Int. 156, no. 2, 255-266.

Vernant, P., F. Nilforoushan, D. Hatzfeld, M. Abbassi, C. Vigny, F. Masson, H. Nankali, J. Martinod, A. Ashtiani, R. Bayer, F. Tavakoli, and J. Chéry (2004). Present-day crustal deformation and plate kinematics in the Middle East constrained by GPS measurements in Iran and northern Oman, Geophys. J. Int. 157, no. 1, 381-398.

Wessel, P., and W. Smith (1991). Free software helps map and display data, Eos Trans. AGU 72, no. 441, 445-446.

Zhao, L., T. Jordan, K. Olsen, and P. Chen (2005). Fréchet kernels for imaging regional Earth structure based on three-dimensional reference models, Bull. Seismol. Soc. Am. 95, no. 6, 2066-2080.
Graduate School of Oceanography

University of Rhode Island

215 South Ferry Road

Narragansett, Rhode Island 02882

(B.M.C.)

Department of Geosciences

University of Rhode Island

317 Woodward Hall

Kingston, Rhode Island 02881

(B.S.)

Manuscript received 30 September 2011 